\title{
LINGUÍSTICA CONTRASTIVA: ESTUDO BIBLIOMÉTRICO NO CONTRASTE DE PB E ESPANHOL COMO LÍNGUA ESTRANGEIRA NO BRASIL, DE 1988 A 2010
}

\author{
CONTRASTIVE LINGUISTICS: A BIBLIOMETRIC STUDY ON THE \\ CONSTRAST OF BRAZILIAN PORTUGUESE AND SPANISH AS A \\ FOREIGN LANGUAGE IN BRASIL, FROM 1988 TO 2010
}

Ana Patrícia Sousa Silva

Mestranda em Linguística - PPGL/UFSC

Resumo

Este trabalho tem por objetivo geral mapear as pesquisas realizadas em Linguística Contrastiva no Brasil que enfatizam o contraste entre o PB e o espanhol, no período de 1988 a 2010 . Na realização deste mapeamento, tem-se como objetivos específicos: (i) categorizar as pesquisas nos modelos de análise da Linguística Contrastiva; (ii) identificar as instituições brasileiras onde se desenvolvem essas pesquisas e (iii) enquadrar as pesquisas conforme a abordagem linguística empregada. Os dados foram obtidos no Banco de Teses da CAPES em novembro de 2011. O critério de busca (sem delimitação de data) usou os seguintes termos combinados: Linguística Contrastiva espanhol; Análise Contrastiva espanhol; Análise de erros espanhol; Interlíngua espanhol; Transferência espanhol; Interferência espanhol e Fossilização espanhol. Encontraramse 111 referências, e sua maior concentração está nas regiões Sul e Sudeste, que apresentam 27 e 64 pesquisas, respectivamente. No concernente à abordagem empregada nesses estudos, privilegiaram-se os aspectos morfossintáticos, apresentando-se como tema recorrente o sistema pronominal das duas línguas. Conclui-se que, nas universidades brasileiras, desenvolveram importantes pesquisas nas abordagens morfossintática, léxico-semântica e fonético-fonológica, no entanto ainda são incipientes os trabalhos que contemplam os aspectos pragmáticos e discursivos.

Palavras-chave: Linguística Contrastiva. Espanhol. Português Brasileiro. Ensino de Língua Estrangeira

\section{Abstract}

This study aims to map researches on Contrastive Linguistics in Brazil that emphasize the contrast between Brazilian Portuguese and Spanish, from 1988 to 2010. The mapping was carried out with the following specific objectives: (i) categorize the researches in the analytical models of Contrastive Linguistics, (ii) identify the Brazilian institutions where those researches are carried out, and (iii) classify the researches according to the linguistic approach employed. This work consists of a bibliographical survey whose data were obtained from the theses database of CAPES in November 2011. The search criterion (without specific date) used the following search terms combined: Contrastive Linguistics Spanish, Contrastive Analysis Spanish, Error Analysis Spanish, Interlanguage Spanish, Transfer Spanish, Interference Spanish, and Fossilization Spanish. The output was a total of 111 studies, whose largest concentration is in the South and Southeast regions of Brazil, featuring 27 and 64 studies, respectively. The preferred approach concerns the morphosyntactic aspects, namely the pronominal system of the two languages. The present study concludes that researches in Brazilian universities have developed important work on the morphosyntactic, lexical-semantic and phonetic-phonological aspects, however the work with pragmatic or discursive approaches is still incipient.

Keywords: Contrastive Linguistics. Spanish. Brazilian Portuguese. Second language teaching. 


\section{INTRODUÇÃO}

O presente estudo versa sobre a Linguística Contrastiva (LC) como também sobre seus modelos de análise - modelo de Análise Contrastiva (AC), modelo de Análise de Erros (AE) e modelo de Interlíngua (IL) - como área de pesquisa desenvolvida pelas universidades brasileiras, no período de 1988 a 2010. A coleta de dados realiza-se no Banco de Tese da CAPES.

O papel desempenhado pela Língua Materna (LM) no processo de aprendizagem de Língua Estrangeira (LE), mais especificamente língua espanhola, vem adquirindo maior relevância no meio acadêmico. Por conseguinte, um levantamento sobre as pesquisas realizadas na área, juntamente com a abordagem empregada nesses estudos, é relevante para aqueles que aspiram realizar investigações nessa área de conhecimento.

A motivação para o desenvolvimento do trabalho surgiu das aulas e discussões da disciplina Tópicos Especiais de Ensino e Aprendizagem de Língua Estrangeira, ministrada pela professora Dra. Adja Balbino de Amorim Barbieri Durão no Programa de Pós-Graduação em Linguística da Universidade Federal de Santa Catarina, no segundo semestre de 2011. A presente pesquisa refere-se a uma das etapas de avaliação dessa disciplina.

Partindo desse cenário, este artigo refere-se a pesquisas desenvolvidas no campo da Linguística Contrastiva por parte de pesquisadores vinculados a programas de pósgraduação em universidades brasileiras, no período que vai de 1988 a 2010 . O estudo tem por objetivo geral mapear as pesquisas realizadas em Linguística Contrastiva no Brasil que enfatizam o contraste entre o PB e o espanhol no período de 1988 a 2010 . Na realização deste mapeamento, tem-se como objetivos específicos: (i) categorizar as pesquisas segundo os modelos de análise da Linguística Contrastiva; (ii) identificar as instituições brasileiras que respondem a essas pesquisas e (iii) enquadrar as pesquisas conforme a abordagem linguística empregada.

Este estudo está divido em três partes: A primeira faz referência ao caráter do estudo, explicitando o critério de busca deste levantamento; a segunda analisa os resultados obtidos; a terceira apresenta as principais constatações do levantamento e traz recomendações para futuras investigações nessa área de estudo.

\section{METODOLOGIA}

No que tange ao enquadramento metodológico, esta é uma pesquisa qualitativa e quantitativa, documental e de natureza descritiva. Quanto à abordagem do problema, esta pesquisa caracteriza-se como qualitativa e quantitativa, porque visa destacar características das pesquisas que enfatizam o contraste entre o PB e o espanhol. Neste tipo de abordagem não se procura apenas apresentar, e sim analisar e discutir os achados da pesquisa, incluindo técnicas estatísticas. Quanto ao procedimento técnico utilizado, esta é uma pesquisa documental (GIL, 2002). A coleta de dados foi realizada com dados secundários (GIL, 2002), constituídos de trabalhos disponíveis no Banco de Teses da CAPES (http://capesdw.capes.gov.br/capesdw/Teses.do), em novembro de 2011. Por fim, quanto ao seu objetivo, esta pesquisa é de natureza descritiva (GIL, 2002), pois procura descrever que aspectos estão sendo estudados. 
Este trabalho enfocou as informações contidas nos resumos, palavras-chave, instituições e orientadores das teses e dissertações do Banco de Teses da CAPES. O critério de busca usou os seguintes termos combinados: Linguística Contrastiva espanhol; Análise Contrastiva espanhol; Análise de erros espanhol; Interlíngua espanhol; Transferência espanhol; Interferência espanhol e Fossilização espanhol. O motivo que levou à inclusão de outros termos além de Linguística Contrastiva (LC) é explicitado no tópico seguinte. Nesse processo, foram excluídas as pesquisas que não faziam referência à perspectiva contrastiva envolvendo o espanhol. Vale ponderar que algumas pesquisas reapareceram mesmo empregando termos de busca diferentes. Assim, este levantamento de dados resultou em um total de 111 referências: 22 teses de doutorado e 89 dissertações de mestrado (v. Anexo).

\section{REFERENCIAL TEÓRICO}

Segundo Vandresen (1988), os estudos realizados na área da Linguística Contrastiva são conhecidos como Análise Contrastiva (AC). Por conseguinte, o termo Análise Contrastiva foi incluído no critério de busca. Houve uma reformulação no estudo da Linguística Contrastiva e, com isso, foram incorporadas as noções Análise de Erros (AE), Interlíngua (IL), Transferência (TR), Interferência (I) e Fossilização (F).

A Linguística Contrastiva, um dos ramos da Linguística Aplicada, busca dar conta dos estudos contrastivos que promovem a visualização das convergências e divergências existentes entre a Língua Materna (LM) e a língua-alvo. O modelo precursor desenvolvido pela Linguística Contrastiva é o de Análise Contrastiva (AC), que nasce da concepção behaviorista de aprendizagem. Este modelo tem como principal conceito a "interferência linguística", isto é, o deslocamento de elementos da LM para a LE, dando ênfase aos elementos fonéticos, morfológicos e sintáticos.

Conforme Durão (2004, p. 15) a teoria comportamentalista de aquisição linguística foi estudada por Skinner (1926) no livro On verbal behavior, que descreve a língua segundo o esquema: estímulo - resposta - recompensa.

Fernández (1997) afirma que o método da AC foi criticado por outras áreas de estudo da linguagem, posto que se limitava à comparação das características formais de pares oracionais, sem levar em consideração a sua função. Ainda, segundo a autora, essas críticas levaram à uma reformulação da $\mathrm{AC}$, que hoje tenta comparar como ocorrem determinadas funções comunicativas nas diversas línguas, levando em conta as categorias universais (pertencentes a todas as línguas).

Como um dos desenvolvimentos da teoria sintática proposta por Chomsky na obra Syntactic Structures (1957), é concebido o modelo de Análise de Erros (AE), que tem como ponto de partida o trabalho desenvolvido por Corder (1967). Segundo Durão (2004), o autor elabora a dicotomia "erros sistemáticos" e "erros não sistemáticos" para levar a cabo seus estudos. O primeiro tipo de erro compreende aqueles produzidos por fatores não linguísticos, como sensação de cansaço, nervosismo, estresse entre outros, e o segundo tipo se deve ao conhecimento deficiente da língua meta. Os erros do aprendiz em termos linguísticos são descobertos e classificados. Este modelo é sustentado pelas bases teóricas da linguística chomskiana e pelas teorias cognitivistas e mentalistas da aprendizagem. 
Outro modelo pertencente à LC é o de Interlíngua (IL), que tem como seu principal pesquisador Selinker. Para o autor, conforme afirma Durão (2004), na mente humana há uma estrutura psicológica latente que entra em funcionamento quando os aprendizes ingressam na aprendizagem de uma LE. Essa estrutura contém cinco processos psicológicos centrais e quatro secundários que interferem na produção linguística dos aprendizes.

No quadro abaixo, podem-se vislumbrar as características de ambos processos:

Quadro 1 - Processos centrais e secundários

\begin{tabular}{|l|l|}
\hline Processos centrais & Processos secundários \\
\hline $\begin{array}{l}\text { Transferência de elementos de LM } \\
\text { para LE }\end{array}$ & Pronúncia ortográfica \\
\hline Transferência de instrução & Pronúncia cognata (ou afim) \\
\hline Uso de estratégias de aprendizagem & Aprendizagem de holofrases \\
\hline Uso de estratégias de comunicação & Hipercorreção \\
\hline Generalização de regras & \\
\hline
\end{tabular}

No concernente à interlíngua de aprendizes de línguas, Selinker (1972) assevera que o fenômeno mais recorrente é o de Fossilização $(F)$. Este fenômeno, conforme o autor, tem como característica o reaparecimento de estruturas de LE que supostamente deveriam ter sido erradicadas.

Embora os modelos apresentem diferenças substanciais, como afirma Durão (2004), o modelo de AC é parcialmente aproveitado no modelo de AE e de IL. A autora assevera que o ideal seria a integração dos ditos modelos.

\section{ANÁLISE DOS RESULTADOS}

Como foi mencionado anteriormente, o procedimento empregado para a coleta das pesquisas é a relação existente entre os termos Linguística Contrastiva (LC), Análise Contrastiva (AC), Análise de Erros (AE), Interlíngua (IL), Transferência (TR), Interferência (I) e Fossilização (F) unidos ao termo espanhol. A pesquisa usou este critério de relação de termos com vistas a um maior detalhamento das pesquisas feitas sob a perspectiva contrastiva.

A pesquisa foi realizada sem delimitação de data, posto que se almejava encontrar a primeira pesquisa que usasse a perspectiva contrastiva entre o $\mathrm{PB}$ e o espanhol. $\mathrm{O}$ resultado aponta que o primeiro estudo é uma dissertação de mestrado que foi desenvolvida na Universidade Federal da Paraíba (UFPR) por Vieira (1988). Após o ano de 1988, observa-se um crescimento no número de dissertações nos anos de 2002, 2006 e 2008, com um total de 10 pesquisas cada. O Gráfico 1, a seguir, demonstra isso: 


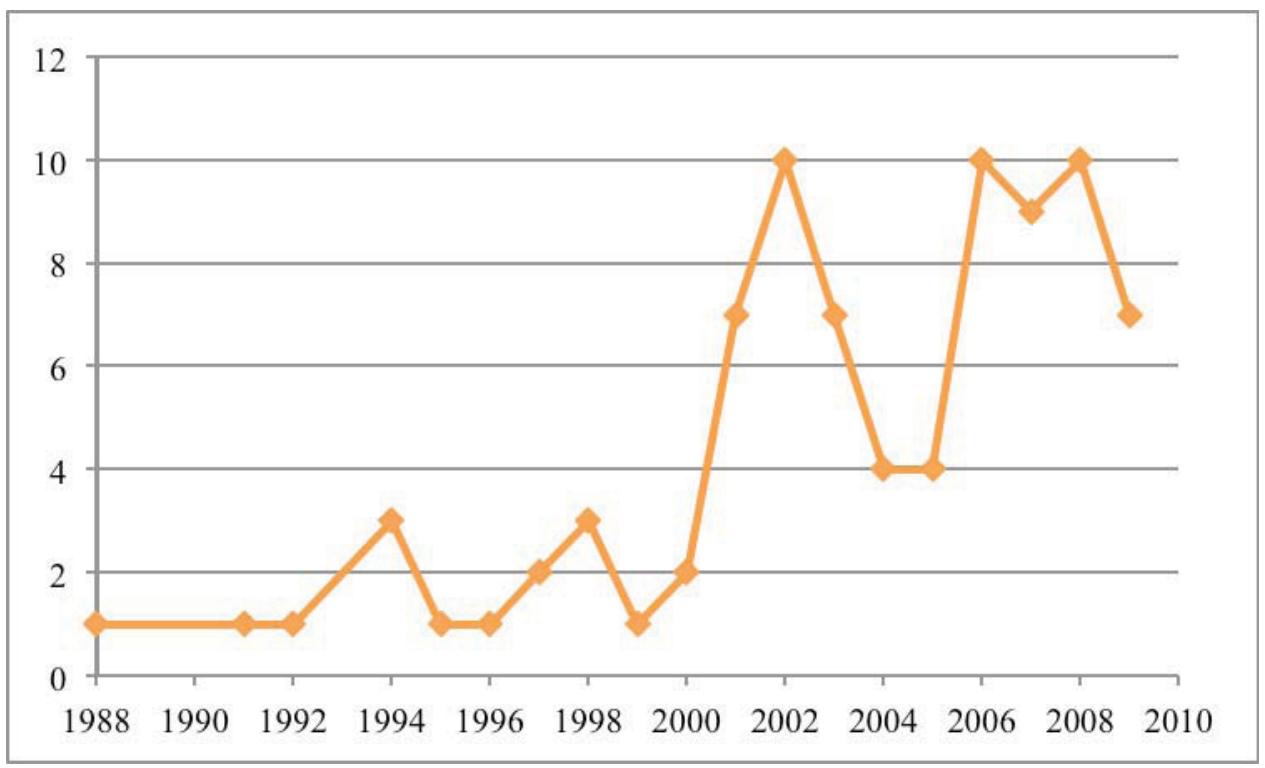

Gráfico 1 - Dissertações em LC por ano.

No que se refere às teses, a primeira pesquisa encontrada sem definição de data foi defendida por González (1994) da Universidade de São Paulo (USP). Até o ano de 2004, registra-se em moda uma publicação por ano. Esse tipo de pesquisa teve no ano de 2008 o seu maior número de produções, com 4 defesas. Os demais dados estão expostos no Gráfico :

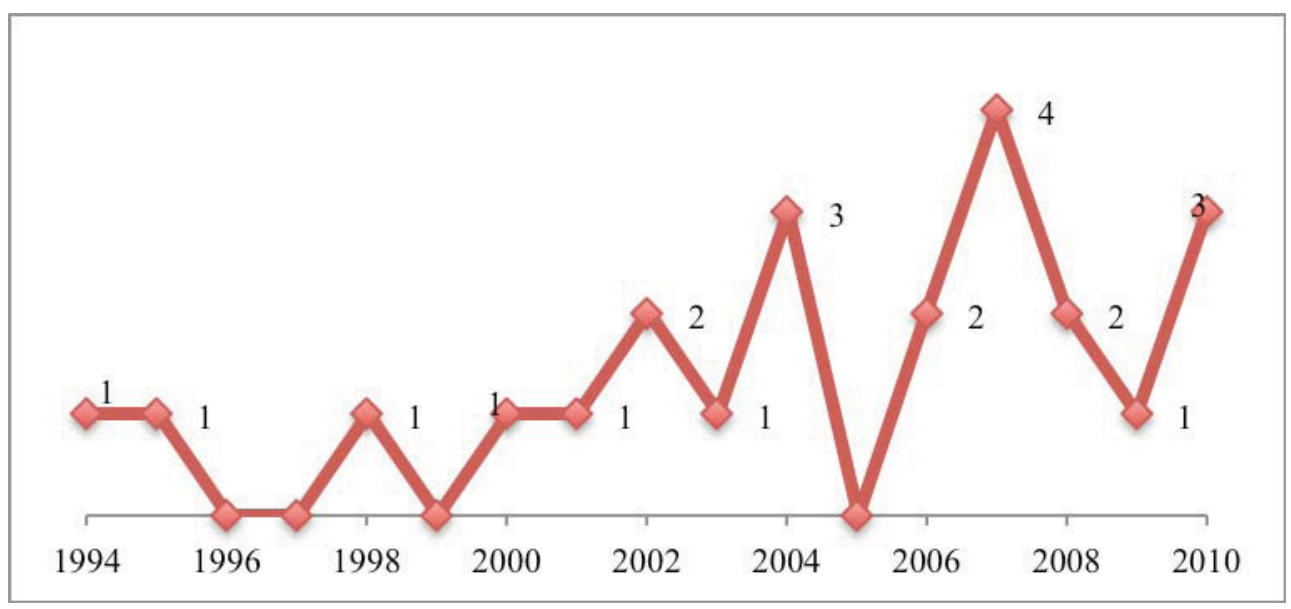

Gráfico 2 - Teses em LC por ano.

As universidades brasileiras que respondem pelo maior número de pesquisas estão concentradas nas regiões Sul e Sudeste, que apresentam 27 e 64 pesquisas, respectivamente. Na região Nordeste, produziram-se 12 pesquisas e na região CentroOeste, 8 pesquisas, sendo 7 na Universidade de Brasilia (UNB). Os estados com maior número de pesquisa são São Paulo, com 52 pesquisas, e Rio Grande do Sul, com 14 pesquisas. O Gráfico 3 relaciona o número de trabalhos às instituições: 


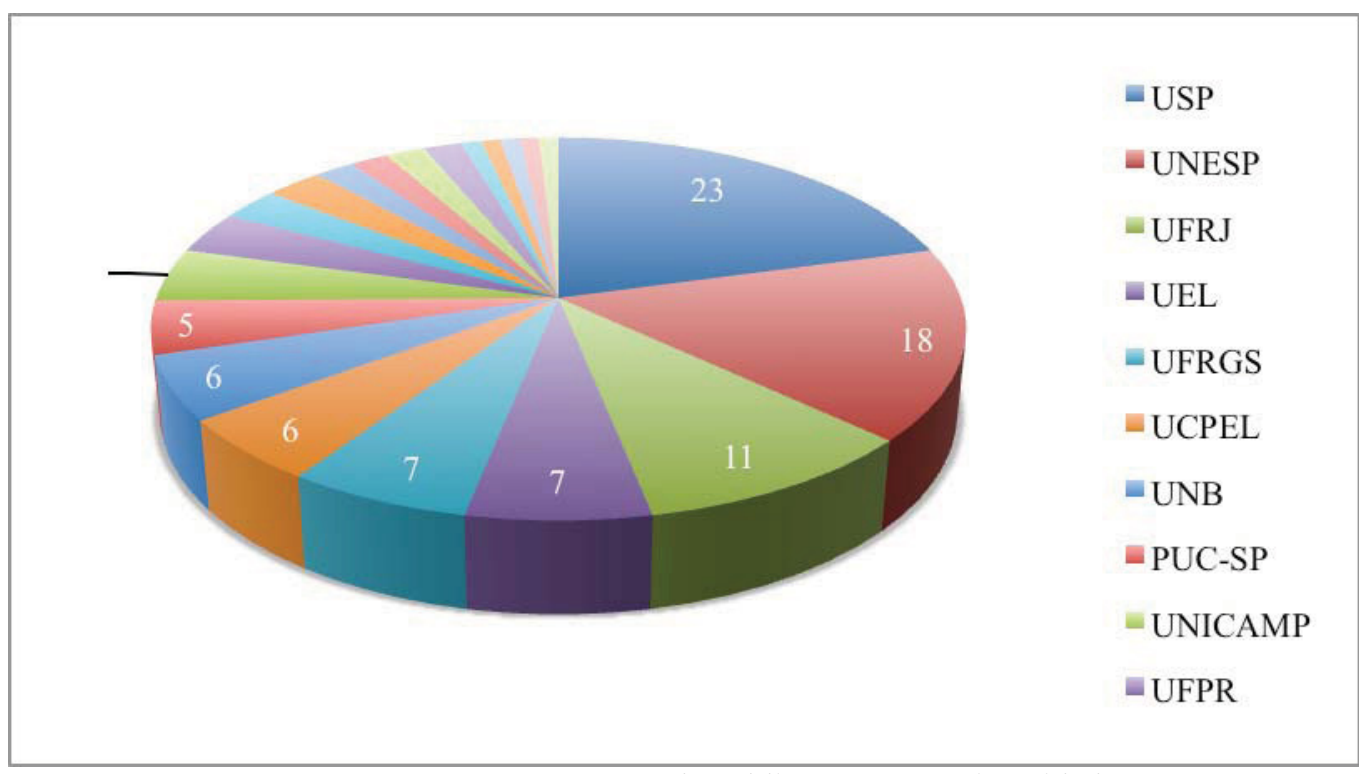

Gráfico 3 - Número de publicações por universidade

Das 111 referências encontradas, 58 pesquisas foram desenvolvidas elegendo somente um termo: 15 pesquisas com foco na Análise Contrastiva (AC), 15 na Interlíngua (IL), 14 concentradas no estudo da Interferência (I), 9 contemplaram o fenômeno da Transferência (TR), 3 fizeram referência à Linguística Contrastiva (LC) e 2 focaram-se na Análise de Erros (AE). Os outros 54 trabalhos foram localizados fazendo-se uma relação entre os termos. Dentre as combinações mais relevantes, encontra-se a relação entre LC e AC, com 19 pesquisas, e entre IL e TR, com 6, como se pode observar no Gráfico .

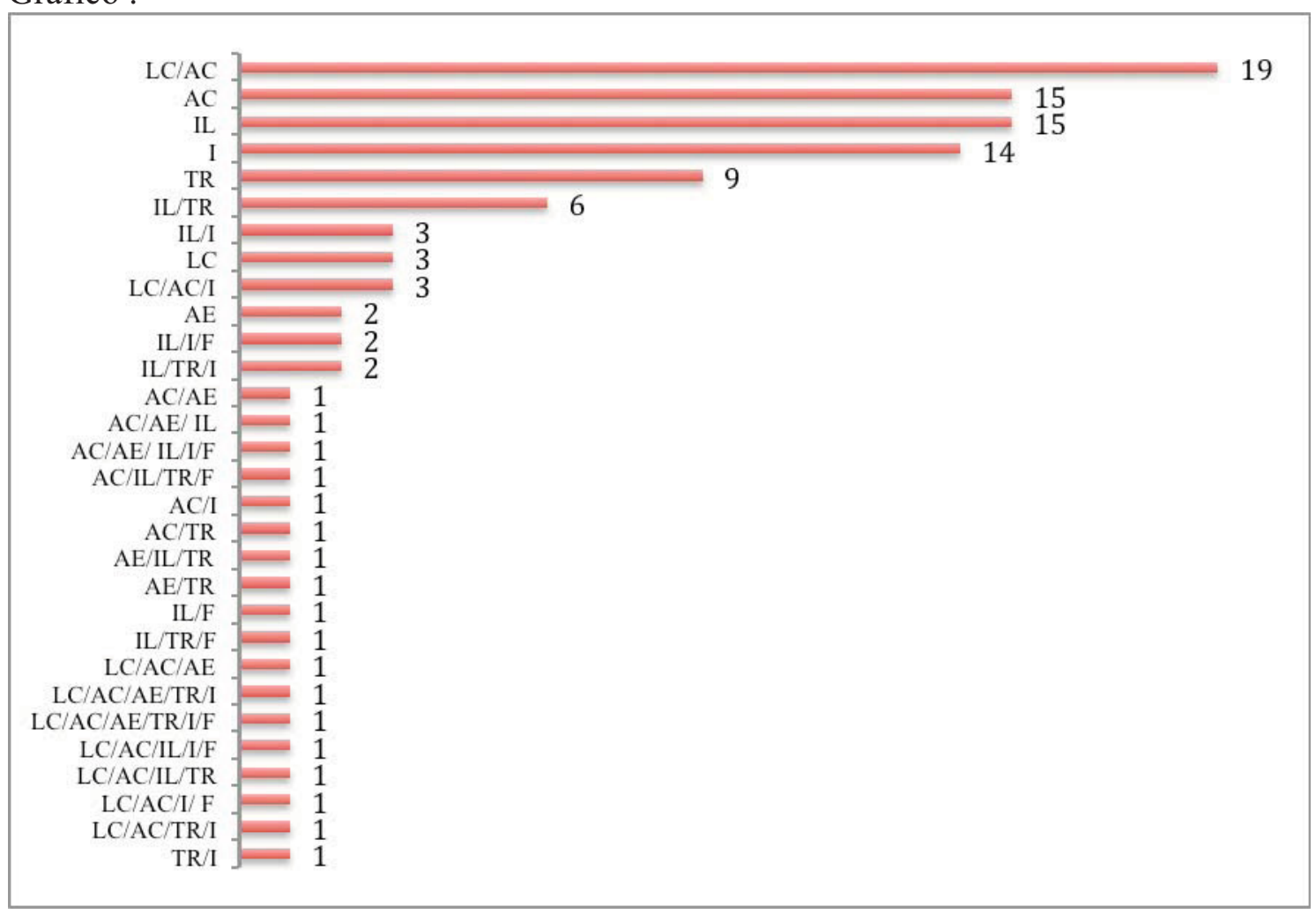

Gráfico 4 - Modelos de Análise presentes nas pesquisas

Quanto às abordagens adotadas nas pesquisas, observa-se uma preferência pelos aspectos morfossintáticos, com 42 pesquisas e, dentre eles, o elemento mais estudado é 
o pronome pessoal, com 11 pesquisas. No que se refere aos aspecto léxico-semânticos, cujo total é de 24 pesquisas há uma prioridade pelo estudo dos falsos cognatos, ou seja, os heterossemânticos, com 7 pesquisas. As investigações dos aspectos discursivos e pragmáticos somam 9 pesquisas. Outros aspectos aparecem. No entanto, como a categorização foi baseada nos resumos, em alguns casos, foi impossível uma classificação precisa. Assim, para evitar o equívoco, optou-se por não incluir essas pesquisas (que totalizaram 12) nas categorias apresentadas no Gráfico 5:

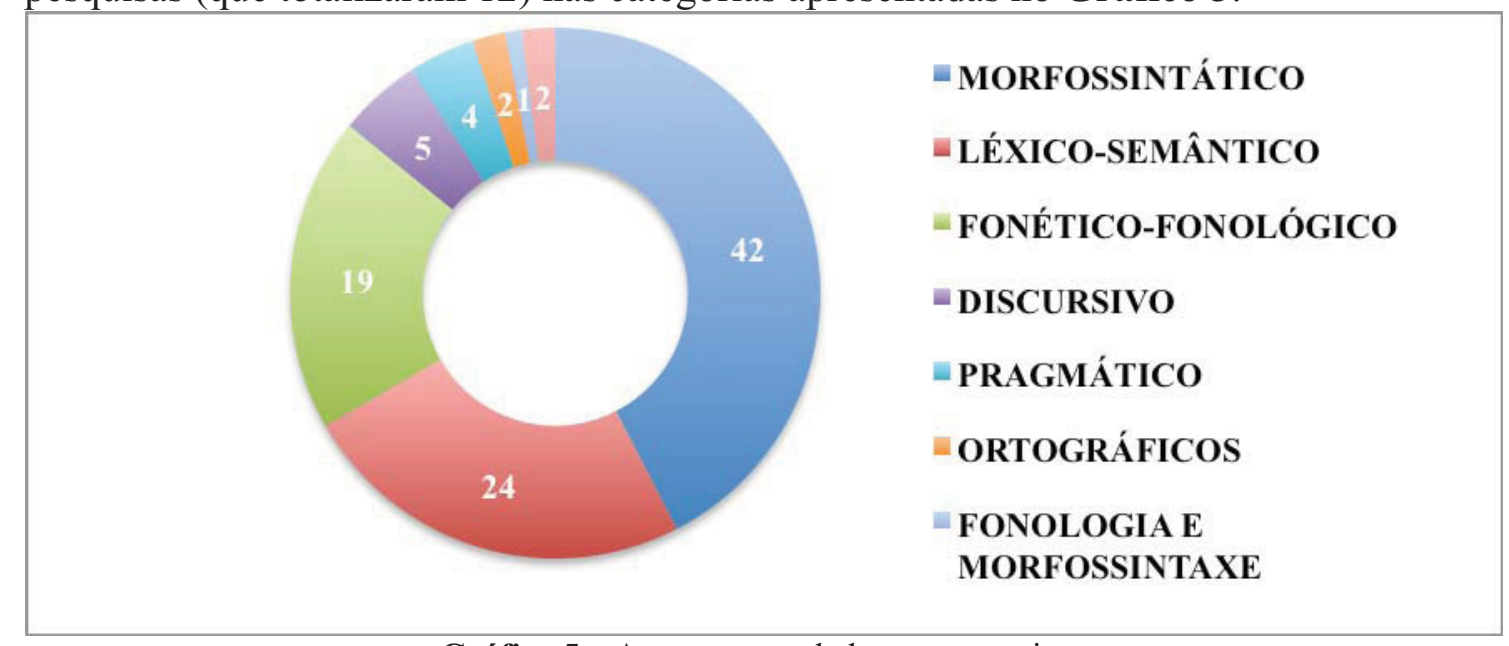

Gráfico 5 - Aspectos estudados nas pesquisas

\section{CONCLUSÕES E SUGESTÕES PARA FUTUROS TRABALHOS}

As pesquisas analisadas e coletadas para a produção deste artigo estão inseridas no Banco de Teses da CAPES, que disponibiliza os resumos das pesquisas. Por conseguinte, estes resumos foram o principal material de análise, limitando o aprofundamento desta pesquisa. Alguns resumos apareceram incompletos, impossibilitando o desenvolvimento de alguns objetivos propostos pelo presente estudo.

No concernente aos objetivos almejados, o presente artigo teve como objetivo geral mapear as pesquisas realizadas em Linguística Contrastiva no Brasil que enfatizam o contraste entre o PB e o espanhol, no período de 1988 a 2010 e teve como resultado 111 referências que utilizaram ora um modelo de análise - LC, AC, AE, IL, I, TR -, ora promoveram a integração mais de um modelo. Os modelos de Análise Contrastiva (AC) e Interlíngua (IL) estão entre os mais pesquisados, o que sugere uma tendência dos pesquisadores em focar a produção dos aprendizes.

A análise de dados revelou também que a maior concentração dos estudos está na região Sudeste, principalmente no estado de São Paulo. Vale ponderar que a única universidade do Brasil que possui um programa específico para estudos de língua espanhola é a USP, e isso pode ter influenciado nos resultados encontrados. Quanto às abordagens estudadas, observou-se uma preferência pela análise morfossintática, léxicosemântica e fonético-fonológica, evidenciando-se concentração de estudos com enfoque no modelo clássico da LC, a Análise Contrastiva (AC) conforme aponta Durão (2004). Poucos foram os trabalhos que se ocuparam dos aspectos pragmáticos e discursivos.

Como sugestões para futuros trabalhos, tem-se: i) maior ênfase a trabalhos que explorem os aspectos discursivos e pragmáticos; ii) no que diz respeito aos aspectos morfossintáticos, exploração de temas relevantes e de difícil entendimento por parte dos

Work. Pap. Linguíst., Florianopolis, n.esp. 01-17, 2011 
aprendizes, como pronomes relativos, conjunções e preposições; iii) nos trabalhos que enfocam a produção escrita dos alunos, emprego da Linguística Textual.

\section{REFERÊNCIAS}

CHOMSKY, N. Syntactic Structures. The Hague: Mouton, 1957.

CORDER, S. P. The significance of learners' errors. In: International Review of Applied Linguistics, v. 5, n. 4. 1967.

DURÃO, A. B. A. B. Os três modelos da linguística contrastiva frente a frente. In: DURÃO, A. B. A. B. (org.). Linguística Contrastiva: teoria e prática. Londrina: Moriá, 2004.

GIL, A. C. Como elaborar projetos de pesquisa. 4. ed. São Paulo: Atlas, 2002.

FERNÁNDEZ, S. Interlengua y análisis de errores en el aprendizaje de español como lengua extranjera. Madrid: Edelsa, 1997.

SELINKER, L. Interlanguage. In: International Review of Applied Linguistics. v.10, n. 3, p. 219-231, 1972.

VANDRESEN, P. Linguística contrastiva e ensino de línguas estrangeiras. In: BOHN, H.; VANDRESEN, P. (Orgs). Tópicos de Linguística Aplicada: o ensino de línguas estrangeiras. Florianópolis: Ed. da UFSC, 1988. 


\section{ANEXO - DISSERTAÇÕES E TESES}

\begin{tabular}{|c|c|c|c|}
\hline & Ano & $\begin{array}{l}\text { Univer- } \\
\text { sidade }\end{array}$ & Mestrado \\
\hline 1 & 1988 & UFPB & $\begin{array}{l}\text { VIEIRA, J. A. M. Analise contrastiva aplicada ao portugues e ao espanhol: } \\
\text { uma abordagem fonético-fonologica. } 1988.209 \text { f. Dissertação (Mestrado em } \\
\text { Letras) - Universidade Federal da Paraíba, João Pessoa, } 1988 .\end{array}$ \\
\hline 2 & 1991 & UFSC & $\begin{array}{l}\text { OLIVEIRA, S. M. Legendação de metáforas: um estudo empírico- } \\
\text { experimental com base no filme La lengua de las mariposas. } 2008.101 \mathrm{f} \text {. } \\
\text { Dissertação (Mestrado em Linguística) - Universidade Federal de Santa } \\
\text { Catarina, Florianópolis, } 1991 .\end{array}$ \\
\hline 3 & 1991 & UFSC & $\begin{array}{l}\text { RAFAEL, C. Níveis de interferência lexical na aprendizagem do espanhol } \\
\text { por estudantes brasileiros. 1991. } 139 \text { f. Dissertação (Mestrado em } \\
\text { Linguística) - Universidade Federal de Santa Catarina, Florianópolis, } 1991 .\end{array}$ \\
\hline 4 & 1992 & UFRJ & $\begin{array}{l}\text { VIANNA, O. O. M. A interferência do espanhol no português do chui- } \\
\text { santa-vitoriense o mergulhão dos pagos. } 1992.142 \text { f. Dissertação (Mestrado } \\
\text { em Linguística) - Universidade Federal do Rio de Janeiro, Rio de Janeiro, } \\
1992 .\end{array}$ \\
\hline 5 & 1994 & $\begin{array}{l}\text { UNICA } \\
\text { MP }\end{array}$ & $\begin{array}{l}\text { BRANDÃO, L. R. Yo hablo. pero... quién corrige? a correção de erros } \\
\text { fonéticos persistentes nas produções em espanhol de aprendizes brasileiros. } \\
\text { 2003. } 239 \text { f. Dissertação (Mestrado em Linguística Aplicada). Universidade } \\
\text { Estadual de Campinas, Campinas, } 1994 \text {. }\end{array}$ \\
\hline 6 & 1994 & UNESP & $\begin{array}{l}\text { DO MAR, G. D. Os sistemas consonânticos do portugues do brasil e do } \\
\text { espanhol peninsular: estudo constrativo fonético-fonológico das normas } \\
\text { cultas. 1994. } 163 \text { f. Dissertação (Mestrado em Letras). Universidade } \\
\text { Estadual Paulista Júlio de Mesquita Filho, Assis, } 1994 .\end{array}$ \\
\hline 7 & 1994 & $\begin{array}{l}\text { UNICA } \\
\mathrm{MP}\end{array}$ & $\begin{array}{l}\text { LEIVA, M. J. S. Falsos cognatos em português e espanhol. 1994. } 166 \text { f. } \\
\text { Dissertação (Mestrado em Linguística Aplicada). Universidade Estadual de } \\
\text { Campinas, Campinas, } 1994 .\end{array}$ \\
\hline 8 & 1994 & USP & $\begin{array}{l}\text { OSORIO, E. M. R. Dificuldades que apresenta o aluno brasileiro ao falar a } \\
\text { língua espanhola - um estudo dos dêiticos. 1994. } 114 \text { f. Dissertação } \\
\text { (Mestrado em Linguística) - Universidade de São Paulo, São Paulo, } 1994\end{array}$ \\
\hline 9 & 1995 & UFRJ & $\begin{array}{l}\text { LIMA, M. R. Variações na interlíngua de falantes de espanhol como lingua } \\
\text { estrangeira. 1995. } 168 \text { f. Dissertação (Mestrado em Letras Neolatinas) - } \\
\text { Universidade Federal do Rio de Janeiro, Rio de Janeiro, } 1995 .\end{array}$ \\
\hline 10 & 1995 & UFRJ & $\begin{array}{l}\text { LIMA, V. C. A. O objeto direto anafórico no português do Brasil: } \\
\text { Evidencias de suas peculiaridades na interlíngua de aprendizes de } \\
\text { espanhol. 2002. } 138 \text { f. Dissertação (Mestrado em Letras) - Universidade } \\
\text { Federal do Rio de Janeiro, Rio de Janeiro, } 1995 \text {. }\end{array}$ \\
\hline 11 & 1997 & UNESP & $\begin{array}{l}\text { CAMPIDELI, E. A. O pronome se: seus usos e funções em português e } \\
\text { espanhol. 1997. } 222 \text { f. Dissertação (Mestrado em Letras). Universidade } \\
\text { Estadual Paulista Júlio de Mesquita Filho, Assis, } 1997 .\end{array}$ \\
\hline 12 & 1997 & UNESP & $\begin{array}{l}\text { CARVALHO, K. C. H. P. Características entonacionais do português e do } \\
\text { espanhol: estudo contrastivo e instrumental. 1998. 188p. Dissertação } \\
\text { (Mestrado em Letras). Universidade Estadual Paulista Júlio de Mesquita } \\
\text { Filho, Assis, } 1997 .\end{array}$ \\
\hline 13 & 1997 & UFRGS & $\begin{array}{l}\text { KONZEN, M. P. O processo de aquisição da regra de palatalização do } \\
\text { português como segunda língua, por falantes nativos de espanhol. } 1997.110 \\
\text { f. Dissertação (Mestrado em Letras) - Universidade Federal do Rio Grande } \\
\text { do Sul, Porto Alegre, } 1997 \text {. }\end{array}$ \\
\hline 14 & 1997 & UNESP & $\begin{array}{l}\text { RONCOLATTO, E. Estudo contrastivo das expressões idiomáticas do } \\
\text { português e do espanhol. 1996. } 87 \text { f. Dissertação (Mestrado em Letras). } \\
\text { Universidade Estadual Paulista Júlio de Mesquita Filho, Assis, } 1997 .\end{array}$ \\
\hline 15 & 1998 & UNESP & $\begin{array}{l}\text { SERÓDIO, M. V. C. S. A preposição espanhola hacia: significados, usos e } \\
\text { equivalências em português e outras línguas. Estudo contrastivo do sistema } \\
\text { preposicional direcional do espanhol e do português. } 1998.132 \mathrm{f} \text {. } \\
\text { Dissertação (Mestrado em Letras). Universidade Estadual Paulista Júlio de } \\
\text { Mesquita Filho, Assis, } 1998 \text {. }\end{array}$ \\
\hline
\end{tabular}

Work. Pap. Linguíst., Florianopolis, n.esp. 01-17, 2011 


\begin{tabular}{|c|c|c|c|}
\hline & Ano & $\begin{array}{l}\text { Univer- } \\
\text { sidade }\end{array}$ & Mestrado \\
\hline 16 & 1999 & UFRGS & $\begin{array}{l}\text { MIGNONI, R. P. L. A transferência e a aquisição das vogais espanholas lel } \\
\text { e /o/, em substantivos e adjetivos por falantes universitários brasileiros. } \\
\text { 1999. } 156 \text { f. Dissertação (Mestrado em Letras) - Universidade Federal do } \\
\text { Rio Grande do Sul, Porto Alegre, } 1999 \text {. }\end{array}$ \\
\hline 17 & 2000 & UNESP & $\begin{array}{l}\text { ANDRADE, O. G. Matizes do verbo português ficar sob a perspectiva da } \\
\text { conjugação dos modelos de análise contrastiva de análise de erros. } 2000 . \\
129 \text { f. Dissertação (Mestrado em Letras) -Universidade Estadual Paulista } \\
\text { Júlio de Mesquita Filho, Assis, 2000. }\end{array}$ \\
\hline 18 & 2000 & UFRJ & $\begin{array}{l}\text { OLIVEIRA, A. M. R. Estratégias de escritura em LE: transferências do } \\
\text { português ao espanhol. } 2000.130 \text { f. Dissertação (Mestrado em Letras } \\
\text { Neolatinas) - Universidade Federal do Rio de Janeiro, Rio de Janeiro, } 2000 .\end{array}$ \\
\hline 19 & 2001 & USP & $\begin{array}{l}\text { ARRUDA, S. A. F. Encadeamento textual, modalização e processos } \\
\text { psicolingüísticos na interlíngua escrita de brasileiros aprendizes de } \\
\text { espanhol. 2002. } 193 \text { f. Dissertação (Mestrado em Linguística). Universidade } \\
\text { de São Paulo, São Paulo, 2001. }\end{array}$ \\
\hline 20 & 2001 & USP & $\begin{array}{l}\text { BRUNO, F. A. T. C. A compreensão da impersonalidad em espanhol por } \\
\text { estudantes brasileiros. 2001. } 230 \text { f. Dissertação (Mestrado em Linguística). } \\
\text { Universidade de São Paulo, São Paulo, 2001. }\end{array}$ \\
\hline 21 & 2001 & USP & $\begin{array}{l}\text { FONSECA, M. C. M. Um estudo das formas verbais de pretérito nas } \\
\text { interlínguas de brasileiros aprendizes do inglês e do espanhol: past simple, } \\
\text { present perfect e pretérito indefinido/pretérito perfecto. 2001. } 400 \mathrm{f} \text {. } \\
\text { Dissertação (Mestrado em Linguística). Universidade de São Paulo, São } \\
\text { Paulo, 2001. }\end{array}$ \\
\hline 22 & 2001 & USP & $\begin{array}{l}\text { GASPAROTTO, E. M. Perspectivas lingüísticas e temporais na análise } \\
\text { contrastiva do gênero cartas comerciais em português e espanhol. } 2001 . \\
252 \text { f. Dissertação (Mestrado em Letras) - Departamento de Letras } \\
\text { Modernas Língua Espanhola e Lit. Espanhola e Hispano-americana. } \\
\text { Universidade de São Paulo, São Paulo, 2001. }\end{array}$ \\
\hline 23 & 2001 & UNESP & $\begin{array}{l}\text { KLEIN, D. J. Os heterossemânticos como elemento complicador na } \\
\text { interface português-espanhol. 2001. } 115 \text { f. Dissertação (Mestrado em } \\
\text { Letras/Linguística e Língua Portuguesa) - Universidade Estadual Paulista } \\
\text { Júlio de Mesquita Filho, Araraquara, 2001. }\end{array}$ \\
\hline 24 & 2001 & UNESP & $\begin{array}{l}\text { MENEGHINI, C. M. A abordagem de Paulo Freire no ensino de espanhol } \\
\text { como língua estrangeira. 2001. } 198 \text { f. Dissertação (Mestrado em Estudos } \\
\text { Linguísticos). Universidade Estadual Paulista Júlio de Mesquita Filho, São } \\
\text { José do Rio Preto, } 2001 .\end{array}$ \\
\hline 25 & 2001 & USP & $\begin{array}{l}\text { SANTOS, V. T. Pronomes pessoais - o uso das formas átonas na produção } \\
\text { escrita de alunos brasileiros aprendizes de espanhol/LE: uma abordagem } \\
\text { teórico-prática. 2001. } 197 \text { f. Dissertação (Mestrado em Educação) - } \\
\text { Universidade de São Paulo, São Paulo, 2001. }\end{array}$ \\
\hline 26 & 2001 & USP & $\begin{array}{l}\text { YOKOTA, R. A marcação de caso acusativo na interlíngua de brasileiros } \\
\text { que estudam o espanhol. 2001. } 191 \text { f. Dissertação (Mestrado em } \\
\text { Linguística). Universidade de São Paulo, São Paulo, } 2001 \text {. }\end{array}$ \\
\hline 27 & 2002 & USP & $\begin{array}{l}\text { ALVAREZ, M. A. G. La oblicuidad, construções de dativo na interlíngua } \\
\text { de estudantes brasileiros de espanhol. 2002. } 134 \text { f. Dissertação (Mestrado } \\
\text { em Letras) - Departamento de Letras Modernas Língua Espanhola e Lit. } \\
\text { Espanhola e Hispano-americana. Universidade de São Paulo, São Paulo, } \\
2002 \text {. }\end{array}$ \\
\hline 28 & 2002 & UEL & $\begin{array}{l}\text { BARREIRA, V. L. O. Tuteo ou voseo? Problemas relacionados ao uso dos } \\
\text { pronomes de tratamento por brasileiros estudantes de espanhol residentes } \\
\text { na fronteira do Brasil com o Paraguai e com a Argentina. 2006. } 134 \mathrm{f} \text {. } \\
\text { Dissertação (Mestrado em Estudos da Linguagem) - Universidade Estadual } \\
\text { de Londrina, Londrina, 2002. }\end{array}$ \\
\hline
\end{tabular}




\begin{tabular}{|c|c|c|c|}
\hline & Ano & $\begin{array}{l}\text { Univer- } \\
\text { sidade }\end{array}$ & Mestrado \\
\hline 29 & 2002 & UNB & $\begin{array}{l}\text { CEBEY, M. M. P. C. O modo do irreal: uma radiografia da interlíngua de } \\
\text { Brasileiros aprendendo espanhol com foco no subjuntivo. 2002. } 150 \mathrm{f} \text {. } \\
\text { Dissertação (Mestrado em Linguística Aplicada). Universidade de Brasília, } \\
\text { Brasília, 2002. }\end{array}$ \\
\hline 30 & 2002 & UNB & $\begin{array}{l}\text { FERNANDES, T. R. P. Um estudo da presença da L1 na escrita inicial e } \\
\text { final de licenciandos em letras/espanhol. } 2002.153 \mathrm{f} \text {. Dissertação (Mestrado } \\
\text { em Linguística Aplicada). Universidade de Brasília, Brasília, 2002. }\end{array}$ \\
\hline 31 & 2002 & UNB & $\begin{array}{l}\text { GOMES, G. P. F. V. Características da interlíngua oral de estudante de } \\
\text { letras/espanhol em anos finais de estudo. 2002. } 184 \mathrm{f} \text {. Dissertação } \\
\text { (Mestrado em Linguística Aplicada). Universidade de Brasília, Brasília, } \\
\text { 2002. }\end{array}$ \\
\hline 32 & 2002 & UEL & $\begin{array}{l}\text { OLIVEIRA, M. A. O futuro do subjuntivo do português e do espanhol : } \\
\text { descrição, confronto, interferência e fossilização. } 2002.152 \text { f. Mestrado. } \\
\text { Dissertação (Mestrado em Letras) - Universidade Estadual de Londrina, } \\
\text { Londrina, 2002. }\end{array}$ \\
\hline 33 & 2002 & UNB & $\begin{array}{l}\text { PASILLAS, A. S. A interlíngua na escrita de brasileiros alunos de nível } \\
\text { avançado de espanhol. } 2002.142 \text { f. Dissertação (Mestrado em Linguística } \\
\text { Aplicada). Universidade de Brasília, Brasília, 2002. }\end{array}$ \\
\hline 34 & 2002 & UEL & $\begin{array}{l}\text { SALOTTI, L. S. ROSSETO. Erros gramaticais em produções escritas de } \\
\text { concluinte do ensino médio: uma análise. 2002. } 128 \mathrm{f} \text {. Dissertação } \\
\text { (Mestrado em Letras) - Departamento de Letras, Universidade Estadual de } \\
\text { Londrina, Londrina, 2002. }\end{array}$ \\
\hline 35 & 2002 & UFG & $\begin{array}{l}\text { SILVA, C. A. M. A competência sociolingüística relacionada com os } \\
\text { americanismos: análise de livros didáticos de E/LE. 2002. } 185 \mathrm{f} \text {. } \\
\text { Dissertação (Mestrado em Letras e Linguística) - Universidade Federal de } \\
\text { Goiás, Goiânia, 2002. }\end{array}$ \\
\hline 36 & 2003 & PUC-SP & $\begin{array}{l}\text { BALBÁS, M. S. Análise de erros, baseada na linguística de corpus, da } \\
\text { escrita de aprendizes brasileiros universitários de espanhol como língua } \\
\text { estrangeira. 2003. 161f. Dissertação (Mestrado em Linguística Aplicada e } \\
\text { Estudos da Linguagem) - Pontifícia Universidade Católica de São Paulo, } \\
\text { São Paulo, 2003. }\end{array}$ \\
\hline 37 & 2003 & UCPEL & $\begin{array}{l}\text { BOÉSSIO, C. P. D. A. Transferência indevida do infinitivo flexionado no } \\
\text { ensino de línguas próximas - português e espanhol. } 2003.110 \text { f. Dissertação } \\
\text { (Mestrado em Letras) - Faculdade de Letras. Universidade Católica De } \\
\text { Pelotas, Pelotas, 2003. }\end{array}$ \\
\hline 38 & 2003 & USP & $\begin{array}{l}\text { BOTTARO, S. E. G. O entreberato, esa língua que inbentemo aqui: o } \\
\text { contínuo lingüístico na região fronteiriça Brasil - Uruguai. 2003. } 411 \mathrm{f} \text {. } \\
\text { Dissertação (Mestrado em Letras) - Departamento de Letras Modernas } \\
\text { Língua Espanhola e Lit. Espanhola e Hispano-americana. Universidade de } \\
\text { São Paulo, São Paulo, 2003. }\end{array}$ \\
\hline 39 & 2003 & UFBA & $\begin{array}{l}\text { MACÊDO, M. G. Dificuldades de estudantes brasileiros na produção de } \\
\text { textos escritos em espanhol. 2003. } 100 \text { f. Dissertação (Mestrado em Letras e } \\
\text { Linguística) - Universidade Federal da Bahia, Salvador, } 2003 \text {. }\end{array}$ \\
\hline 40 & 2003 & UFRJ & $\begin{array}{l}\text { SILVA, S. A. Estudo da interface fonologia/morfologia em espanhol } \\
\text { segundo a fonologia lexical. 2003. } 99 \text { f. Dissertação (Mestrado em Letras } \\
\text { Neolatinas) - Universidade Federal do Rio de Janeiro, Rio de Janeiro, } 2003 .\end{array}$ \\
\hline 41 & 2003 & UNB & $\begin{array}{l}\text { SUÁREZ, J. P. Vinculação possível entre natureza de abordagem, perfil e } \\
\text { quantidade de erros na aprendizagem de espanhol para Brasileiros. } 2003 . \\
176 \text { f. Dissertação (Mestrado em Linguística Aplicada). Universidade de } \\
\text { Brasília, Brasília, 2003. }\end{array}$ \\
\hline 42 & 2004 & USP & $\begin{array}{l}\text { BARROS, R. M. Análise contrastiva dos dativos não-argumentais em } \\
\text { português e espanhol. 2004. } 139 \text { f. Dissertação (Mestrado em Educação) - } \\
\text { Universidade de São Paulo, São Paulo, 2004. }\end{array}$ \\
\hline
\end{tabular}




\begin{tabular}{|c|c|c|c|}
\hline & Ano & $\begin{array}{l}\text { Univer- } \\
\text { sidade }\end{array}$ & Mestrado \\
\hline 43 & 2004 & USP & $\begin{array}{l}\text { LIMA, E. I. A. S. Presença do infinitivo flexionado do português no } \\
\text { espanhol : um estudo das orações adverbiais produzidas por estudantes } \\
\text { brasileiros aprendizes do espanhol como língua estrangeira. 2004. } 114 \mathrm{f} \text {. } \\
\text { Dissertação (Mestrado em Letras) - Departamento de Letras Modernas } \\
\text { Língua Espanhola e Lit. Espanhola e Hispano-americana. Universidade de } \\
\text { São Paulo, São Paulo, 2004. }\end{array}$ \\
\hline 44 & 2004 & PUC-SP & $\begin{array}{l}\text { OLIVEIRA, R. A. D. A imagem empresarial e seus diferentes públicos num } \\
\text { evento de fusão corporativa: um estudo em espanhol. } 2004.160 \text { f. } \\
\text { Dissertação (Mestrado em Linguística Aplicada e Estudos da Linguagem) - } \\
\text { Pontifícia Universidade Católica de São Paulo, São Paulo, } 2004 \text {. }\end{array}$ \\
\hline 45 & 2004 & PUC-SP & $\begin{array}{l}\text { SILVA, J. J. A. Os Pronomes pessoais em espanhol e em português: um } \\
\text { estudo contrastivo sob a perspectiva sistêmico-funcional. 2004. } 128 \mathrm{f} \text {. } \\
\text { Dissertação (Mestrado em Linguística Aplicada e Estudos da Linguagem) - } \\
\text { Pontifícia Universidade Católica de São Paulo, São Paulo, 2004. }\end{array}$ \\
\hline 46 & 2005 & UFPR & $\begin{array}{l}\text { DELONG, S. R. As estratégias cognitivas: frames e esquemas no processo } \\
\text { de leitura compreensiva em espanhol como língua estrangeira. 2005. } 167 \mathrm{f} \text {. } \\
\text { Dissertação (Mestrado em Letras). Universidade Federal do Paraná, } \\
\text { Curitiba, } 2005 .\end{array}$ \\
\hline 47 & 2005 & $\begin{array}{l}\text { UNISIN } \\
\text { OS }\end{array}$ & $\begin{array}{l}\text { DOMINGUEZ, M. I. L. Aprendizagem da língua espanhola por crianças de } \\
2^{a} \text { a } 4^{a} \text { série: aspectos fonético-fonológicos. 2005. } 145 \mathrm{f} \text {. Dissertação } \\
\text { (Mestrado em Linguística Aplicada). Universidade do Vale do Rio dos } \\
\text { Sinos, São Leopoldo, } 2005 \text {. }\end{array}$ \\
\hline 48 & 2005 & UCPEL & $\begin{array}{l}\text { FESTUGATTO, M. M. Interferências da língua talian no aprendizado do } \\
\text { espanhol: um estudo de caso. 2005. } 128 \mathrm{f} \text {. Dissertação (Mestrado em Letras) } \\
\text { - Faculdade de Letras. Universidade Católica De Pelotas, Pelotas, } 2005 \text {. }\end{array}$ \\
\hline 49 & 2005 & UFPR & $\begin{array}{l}\text { FRIGO, K. C. Os semelhantes se atraem? Um estudo sobre a aprendizagem } \\
\text { da língua espanhola por falantes brasileiros: caso de transferência. } 2006 . \\
111 \text { f. Dissertação (Mestrado em Letras). Universidade Federal do Paraná, } \\
\text { Curitiba, 2005. }\end{array}$ \\
\hline 50 & 2005 & UFRGS & $\begin{array}{l}\text { PACHECO, S. A. Classificação das palavras malsonantes em dicionários } \\
\text { bilíngües escolares espanhol-português/português-espanhol. } 2005.172 \mathrm{f} \text {. } \\
\text { Dissertação (Mestrado em Letras) - Universidade Federal do Rio Grande do } \\
\text { Sul, Porto Alegre, } 2005 \text {. }\end{array}$ \\
\hline 51 & 2006 & PUC-SP & $\begin{array}{l}\text { ALONSO, M. C. G. P. Corpus lingüístico e a aquisição de falsos cognatos } \\
\text { em espanhol como língua estrangeira. 2006. } 253 \text { f. Dissertação (Mestrado } \\
\text { em Linguística Aplicada e Estudos da Linguagem) - Pontifícia } \\
\text { Universidade Católica de São Paulo, São Paulo, } 2006 .\end{array}$ \\
\hline 52 & 2006 & UNESP & $\begin{array}{l}\text { DELVIZIO, I. A. Equivalência lexical e aspectos morfológicos de termos } \\
\text { em português e espanhol do domínio da dermatologia. } 2006.139 \mathrm{f} \text {. } \\
\text { Dissertação (Mestrado em Estudos Linguísticos). Universidade Estadual } \\
\text { Paulista Júlio de Mesquita Filho, São José do Rio Preto, 2006. }\end{array}$ \\
\hline 53 & 2006 & UFRJ & $\begin{array}{l}\text { GOMES, R. L. R. Posposição do sujeito no português e no espanhol: um } \\
\text { estudo contrastivo. 2006. } 151 \text { f. Dissertação (Mestrado em Linguística) - } \\
\text { Universidade Federal do Rio de Janeiro, Rio de Janeiro, 2006. }\end{array}$ \\
\hline 54 & 2006 & USP & $\begin{array}{l}\text { LIMA, E. M. O processamento da concordância em espanhol/língua } \\
\text { estrangeira nas produções de brasileiros adultos. } 2006.134 \mathrm{f} \text {. Dissertação } \\
\text { (Mestrado em Letras) - Departamento de Letras Modernas Língua } \\
\text { Espanhola e Lit. Espanhola e Hispano-americana. Universidade de São } \\
\text { Paulo, São Paulo, 2006. }\end{array}$ \\
\hline 55 & 2006 & UCPEL & $\begin{array}{l}\text { LOOSE, R. E. O papel da instrução explícita na aquisição/aprendizagem de } \\
\text { estruturas do espanhol por falantes do português. 2006. } 106 \text { f. Dissertação } \\
\text { (Mestrado em Letras) - Faculdade de Letras. Universidade Católica De } \\
\text { Pelotas, Pelotas, 2006. }\end{array}$ \\
\hline
\end{tabular}




\begin{tabular}{|c|c|c|c|}
\hline & Ano & $\begin{array}{l}\text { Univer- } \\
\text { sidade }\end{array}$ & Mestrado \\
\hline 56 & 2006 & USP & $\begin{array}{l}\text { MENEZES, A. S. Sangue de amor correspondido X Sangre de amor } \\
\text { correspondido: análise de um caso emblemático de contato entre PB e o E. } \\
\text { 2006. } 138 \text { f. Dissertação (Mestrado em Letras) - Departamento de Letras } \\
\text { Modernas Língua Espanhola e Lit. Espanhola e Hispano-americana. } \\
\text { Universidade de São Paulo, São Paulo, 2006. }\end{array}$ \\
\hline 57 & 2006 & UCPEL & $\begin{array}{l}\text { OLIVEIRA, G. T. Análise de erros de aprendizagem no idioma espanhol, } \\
\text { por alunos do ensino fundamental e médio: o caso dos pronomes pessoais } \\
\text { átonos. 2006. } 148 \text { f. Dissertação (Mestrado em Letras) - Faculdade de } \\
\text { Letras. Universidade Católica De Pelotas, Pelotas, 2006. }\end{array}$ \\
\hline 58 & 2006 & UCPEL & $\begin{array}{l}\text { SANTOS, A. M. Análise de erros Gramaticais na produção escrita de } \\
\text { aprendizes brasileiros de espanhol: o papel da língua materna. } 2006195 \mathrm{f} . \\
\text { Mestrado. Dissertação (Mestrado em Letras) - Faculdade de Letras. } \\
\text { Universidade Católica De Pelotas, Pelotas, 2006. }\end{array}$ \\
\hline 59 & 2006 & USP & $\begin{array}{l}\text { VITA, C. P. A opacidade da suposta transparência: quando 'amigos' } \\
\text { funcionam como 'falsos amigos. 2006. } 184 \text { f. Dissertação (Mestrado em } \\
\text { Letras) - Departamento de Letras Modernas Língua Espanhola e Lit. } \\
\text { Espanhola e Hispano-americana. Universidade de São Paulo, São Paulo, } \\
\text { 2006. }\end{array}$ \\
\hline 60 & 2007 & UFRGS & $\begin{array}{l}\text { BUENO, R. E. Desenho da microestrutura de um dicionário monolíngüe de } \\
\text { espanhol para estudantes brasileiros: o tratamento da valência verbal. } \\
\text { 2007. } 221 \text { f. Dissertação (Mestrado em Letras) - Universidade Federal do } \\
\text { Rio Grande do Sul, Porto Alegre, } 2007 \text {. }\end{array}$ \\
\hline 61 & 2007 & UECE & $\begin{array}{l}\text { FARIAS, M. S. F. Estudo da interlíngua de brasileiros estudantes de } \\
\text { espanhol apoiado na análise de erros. } 2007.130 \text { f. Dissertação (Mestrado } \\
\text { em Linguística Aplicada) - Departamento de Letras, Universidade Estadual } \\
\text { do Ceará, Fortaleza, 2007. }\end{array}$ \\
\hline 62 & 2007 & USP & $\begin{array}{l}\text { JR, B. J. A. As passivas na produção escrita de brasileiros aprendizes de } \\
\text { espanhol como língua estrangeira. 2007. } 111 \text { f. Dissertação (Mestrado em } \\
\text { Letras) - Departamento de Letras Modernas Língua Espanhola e Lit. } \\
\text { Espanhola e Hispano-americana. Universidade de São Paulo, São Paulo, } \\
\text { 2007. }\end{array}$ \\
\hline 63 & 2007 & UCPEL & $\begin{array}{l}\text { KREBS, M. E. Um olhar para a interferência dos heterossemânticos na } \\
\text { aprendizagem do espanhol por falantes nativos de português brasileiro: um } \\
\text { estudo de caso. } 2007.147 \text { f. Dissertação (Mestrado em Letras) - Faculdade } \\
\text { de Letras. Universidade Católica De Pelotas, Pelotas, } 2007 \text {. }\end{array}$ \\
\hline 64 & 2007 & PUC-RJ & $\begin{array}{l}\text { MARCILESE. M. Aquisição de complementos pronominais acusativos: um } \\
\text { estudo experimental contrastivo entre o Português Brasileiro e o Espanhol } \\
\text { Rio-platense. } 2007.155 \text { f. Dissertação (Mestrado em Letras) - Departamento } \\
\text { de Letras, Pontífica Universidade Católica do Rio de Janeiro, Rio de Janeiro, } \\
2007 .\end{array}$ \\
\hline 65 & 2007 & UFC & $\begin{array}{l}\text { NASCIMENTO, M. V. F. Autoria e posicionamento na produção textual } \\
\text { escrita de futuros professores de espanhol como língua estrangeira. } 2007 . \\
105 \text { f. Dissertação (Mestrado em Linguística) - Universidade Federal do } \\
\text { Ceará, Fortaleza, 2007. }\end{array}$ \\
\hline 66 & 2007 & UFRGS & $\begin{array}{l}\text { RODRIGUEZ, M. N. A aquisição do presente e do pretérito indefinido do } \\
\text { espanhol por alunos brasileiros. } 2007.107 \text { f. Dissertação (Mestrado em } \\
\text { Letras) - Universidade Federal do Rio Grande do Sul, Porto Alegre, } 2007 .\end{array}$ \\
\hline 67 & 2007 & UFC & $\begin{array}{l}\text { SILVA, K. C. D. Ensino-aprendizagem do espanhol: o uso interlingüístico } \\
\text { das vibrantes. 2007. } 160 \text { f. Dissertação (Mestrado em Linguística) - } \\
\text { Universidade Federal do Ceará, Fortaleza, } 2007 .\end{array}$ \\
\hline 68 & 2007 & PUC-SP & $\begin{array}{l}\text { ZEULLI, E. Apresentação oral nas aulas de língua espanhola: desempenho } \\
\text { lingüístico, fatores afetivos e avaliação da atividade. } 2007.112 \mathrm{f} \text {. } \\
\text { Dissertação (Mestrado em Linguística Aplicada e Estudos da Linguagem) - } \\
\text { Pontifícia Universidade Católica de São Paulo, São Paulo, } 2007 \text {. }\end{array}$ \\
\hline
\end{tabular}




\begin{tabular}{|c|c|c|c|}
\hline & Ano & $\begin{array}{l}\text { Univer- } \\
\text { sidade }\end{array}$ & Mestrado \\
\hline 69 & 2008 & UFRGS & $\begin{array}{l}\text { BENEDUZI, R. Colocações substantivo + adjetivo: propostas para sua } \\
\text { identificação e tratamento lexicográfico em dicionários ativos português- } \\
\text { espanhol. } 2008.212 \text { f. Dissertação (Mestrado em Letras) - Universidade } \\
\text { Federal do Rio Grande do Sul, Porto Alegre, } 2008 \text {. }\end{array}$ \\
\hline 70 & 2008 & UEL & $\begin{array}{l}\text { FRANCIS, M. G. Estudo metalexicográfico de falsos amigos do português } \\
\text { em relação ao espanhol em dicionários bilíngues gerais e em dicionários de } \\
\text { falsos amigos. 2010. } 151 \text { f. Dissertação (Mestrado em Estudos da } \\
\text { Linguagem) - Universidade Estadual de Londrina, Londrina, 2008. }\end{array}$ \\
\hline 71 & 2008 & UNB & $\begin{array}{l}\text { FREITAS, M. C. M. A. Duas abordagens em harmonia ou conflito? O } \\
\text { professor e o MD em um curso de formação de E/LE. } 2008.192 \mathrm{f} \text {. } \\
\text { Dissertação (Mestrado em Linguística Aplicada). Universidade de Brasília, } \\
\text { Brasília, 2008. }\end{array}$ \\
\hline 72 & 2008 & UNICAP & $\begin{array}{l}\text { LIMA, J. C. N. Interlíngua: aspectos fonéticos e fonológicos na } \\
\text { aprendizagem no espanhol como língua estrangeira. 2008. } 94 \text { f. Dissertação } \\
\text { (Mestrado em Ciências da Linguagem) - Universidade Católica de } \\
\text { Pernambuco, Recife, 2008. }\end{array}$ \\
\hline 73 & 2008 & UFAL & $\begin{array}{l}\text { OLIVEIRA, A. V. B. H. Estudo fonético-fonológico contrastivo entre a } \\
\text { língua portuguesa falada no Brasil e a língua espanhola. } 2009.101 \mathrm{f} \text {. } \\
\text { Dissertação (Mestrado em Letras e Linguística) - Universidade Federal de } \\
\text { Alagoas, Maceió, } 2008 \text {. }\end{array}$ \\
\hline 74 & 2008 & UEL & $\begin{array}{l}\text { ORTIGOZA, A. F. A contextualização sociolingüística e histórico-política } \\
\text { como explicação para usos e sentidos de unidades léxicas ideologicamente } \\
\text { marcadas: uma análise contrastiva do Espanhol considerado padrão em } \\
\text { relação à variante lingüística falada em Cuba. } 2008.143 \mathrm{f} \text {. Dissertação } \\
\text { (Mestrado em Estudos da Linguagem) - Universidade Estadual de Londrina, } \\
\text { Londrina, } 2008 \text {. }\end{array}$ \\
\hline 75 & 2008 & UFBA & $\begin{array}{l}\text { PINTO, C. F. C. Uma análise das construções de clivagem e outras } \\
\text { construções focalizadoras no espanhol atual. 2008. 191 f. Dissertação } \\
\text { (Mestrado em Letras e Linguística) - Universidade Federal da Bahia, } \\
\text { Salvador, 2008. }\end{array}$ \\
\hline 76 & 2008 & UFRJ & $\begin{array}{l}\text { SA, P. C. F. Análise entonacional de enunciados assertivos, continuativos e } \\
\text { interrogativos lidos em piadas: espanhol /LE e espanhol/LM. 2008. } 182 \mathrm{f} \text {. } \\
\text { Dissertação (Mestrado em Letras Neolatinas) - Universidade Federal do Rio } \\
\text { de Janeiro, Rio de Janeiro, 2008. }\end{array}$ \\
\hline 77 & 2008 & UFRJ & $\begin{array}{l}\text { SANTOS, G. F. Contato lingüístico na região de fronteira Brasil/ Uruguai: } \\
\text { a entoação dialetal em enunciados assertivos e interrogativos do português } \\
\text { e do espanhol. } 2008.210 \text { f. Dissertação (Mestrado em Letras Neolatinas) - } \\
\text { Universidade Federal do Rio de Janeiro, Rio de Janeiro, } 2008 .\end{array}$ \\
\hline 78 & 2008 & UNESP & $\begin{array}{l}\text { SILVA, A. C. O desenvolvimento intra-interlingüístico intandem a distância } \\
\text { (português e espanhol). 2008. } 429 \text { f. Dissertação (Mestrado em Estudos } \\
\text { Linguísticos). Universidade Estadual Paulista Júlio de Mesquita Filho, São } \\
\text { José do Rio Preto, } 2008 .\end{array}$ \\
\hline 79 & 2008 & UFAL & $\begin{array}{l}\text { SILVA, E. B. Análise contrastiva de aspectos fonológicos de heterotônicos } \\
\text { entre português e espanhol. 2008. } 92 \text { f. Dissertação (Mestrado em Letras e } \\
\text { Linguística) - Universidade Federal de Alagoas, Maceió, } 2008 .\end{array}$ \\
\hline 80 & 2009 & UNESP & $\begin{array}{l}\text { COSTA, L. R. A tradução juramentada espanhol- português de atas de } \\
\text { assembléia de associados: questões de equivalência terminológica. } 2009 . \\
143 \text { f. Dissertação (Mestrado em Estudos Linguísticos). Universidade } \\
\text { Estadual Paulista Júlio de Mesquita Filho, São José do Rio Preto, 2009. }\end{array}$ \\
\hline 81 & 2009 & USP & $\begin{array}{l}\text { FERNANDEZ, C. E. G. O subjuntivo em espanhol/LE: contribuição ao seu } \\
\text { ensino a alunos de cursos livres em nível avançado. 2009. } 269 \text { f. Dissertação } \\
\text { (Mestrado em Educação) - Universidade de São Paulo, São Paulo, } 2009 .\end{array}$ \\
\hline 82 & 2009 & UFPR & $\begin{array}{l}\text { FOTI, L. B. S. Formas de tratamento no espanhol de buenos aires } \\
\text { (argentina) e no português de Curitiba (Brasil): subsídios para o ensino de } \\
\text { espanhol para brasileiros. 2009. } 120 \mathrm{f} \text {. Dissertação (Mestrado em Letras). } \\
\text { Universidade Federal do Paraná, Curitiba, } 2009 \text {. }\end{array}$ \\
\hline
\end{tabular}




\begin{tabular}{|c|c|c|c|}
\hline & Ano & $\begin{array}{l}\text { Univer- } \\
\text { sidade }\end{array}$ & Mestrado \\
\hline 83 & 2009 & UFG & $\begin{array}{l}\text { SCHUSTER, L. Erros fonéticos persistentes na produção em espanhol } \\
\text { como língua estrangeira: um estudo com alunos do centro-oeste brasileiro. } \\
\text { 2009. } 100 \text { f. Dissertação (Mestrado em Letras e Linguística) - Universidade } \\
\text { Federal de Goiás, Goiânia, } 2009 \text {. }\end{array}$ \\
\hline 84 & 2009 & UNESP & $\begin{array}{l}\text { SENA, K. A. A tradução juramentada espanhol-português de estatutos } \\
\text { sociais: questões de equivalência terminológica. 2009. } 215 \text { f. Dissertação } \\
\text { (Mestrado em Estudos Linguísticos). Universidade Estadual Paulista Júlio } \\
\text { de Mesquita Filho, São José do Rio Preto, 2009. }\end{array}$ \\
\hline 85 & 2009 & UNESP & $\begin{array}{l}\text { SILVA, A. S. A gramática de valências como proposta para uma } \\
\text { diferenciação entre actantes e circunstantes em português e espanhol. } 1988 . \\
196 \text { f. Dissertação (Mestrado em Letras). Universidade Estadual Paulista } \\
\text { Júlio de Mesquita Filho, Assis, 1998. }\end{array}$ \\
\hline 86 & 2009 & UFRJ & $\begin{array}{l}\text { SILVA, A. S. Entre correspondências e interferências: o tratamento na } \\
\text { região fronteiriça Uruguai-Brasil no século XIX. 2009. } 133 \text { f. Dissertação } \\
\text { (Mestrado em Letras Neolatinas) - Universidade Federal do Rio de Janeiro, } \\
\text { Rio de Janeiro, } 2009 .\end{array}$ \\
\hline 87 & 2010 & UNESP & $\begin{array}{l}\text { DEL LAMA, E. C. A motivação iônica na interface entre o português e o } \\
\text { espanhol. 2010. } 210 \text { f. Dissertação (Mestrado em Letras/Linguística e } \\
\text { Língua Portuguesa) - Universidade Estadual Paulista Júlio de Mesquita } \\
\text { Filho, Araraquara, 2010. }\end{array}$ \\
\hline 88 & 2010 & USP & $\begin{array}{l}\text { FERRO, G. B. M. A poesia desterritorializante de Néstor Perlongher-uma } \\
\text { leitura de Hule. } 2010.130 \text { f. Dissertação (Mestrado em Letras) - } \\
\text { Departamento de Letras Modernas Língua Espanhola e Lit. Espanhola e } \\
\text { Hispano-americana. Universidade de São Paulo, São Paulo, 2010. }\end{array}$ \\
\hline 89 & 2010 & UNESP & $\begin{array}{l}\text { SABATIN, J. D. A ordem sv/vs no português como l2 na fronteira } \\
\text { brasil/paraguai: uma investigação sociofuncionalista na interface } \\
\text { variação/aquisição. 2010. } 99 \text { f. Dissertação (Mestrado em Estudos } \\
\text { Linguísticos). Universidade Estadual Paulista Júlio de Mesquita Filho, São } \\
\text { José do Rio Preto, 2010. }\end{array}$ \\
\hline
\end{tabular}




\begin{tabular}{|c|c|c|c|}
\hline & Ano & $\begin{array}{l}\text { Univer- } \\
\text { sidade }\end{array}$ & Doutorado \\
\hline 1 & 1994 & USP & $\begin{array}{l}\text { GONZALEZ, N. T. M. Cadê o pronome? O gato comeu. Os pronomes } \\
\text { pessoais na aprendizagem do espanhol por brasileiros adultos. 1994. } 451 \mathrm{f} \text {. } \\
\text { Tese (Doutorado em Linguística) - Universidade de São Paulo, São Paulo, } \\
1994\end{array}$ \\
\hline 2 & 1995 & UFPE & $\begin{array}{l}\text { MASIP, V. Dificuldades segmentais de brasileiros recifenses estudantes de } \\
\text { espanhol. 1995. } 626 \mathrm{f} \text {. Tese (Doutorado em Letras) - Universidade Federal } \\
\text { de Pernambuco, Recife, } 1995 \text {. }\end{array}$ \\
\hline 3 & 1998 & USP & $\begin{array}{l}\text { FERNÁNDEZ, I. G. M. E. O imperativo verbal espanhol - estudo das } \\
\text { estratégias utilizadas no seu uso por luso-falantes brasileiros. 1998. } 303 \mathrm{f} \text {. } \\
\text { Tese (Doutorado em Educação) - Universidade de São Paulo, São Paulo, } \\
\text { 1998. }\end{array}$ \\
\hline 4 & 2000 & $\begin{array}{l}\text { UNICA } \\
\text { MP }\end{array}$ & $\begin{array}{l}\text { ALVAREZ, M. L. O. Expressões idiomáticas do português do Brasil e do } \\
\text { espanhol de cuba: estudo contrastivo e implicações para o ensino de } \\
\text { português como língua estrangeira. 2000. } 291 \text { f. Tese (Doutorado em } \\
\text { Linguística Aplicada) - Universidade Estadual de Campinas, Campinas, } \\
2000 .\end{array}$ \\
\hline 5 & 2001 & $\begin{array}{l}\text { UNICA } \\
\text { MP }\end{array}$ & $\begin{array}{l}\text { CRUZ, M. L. O. B. Estágios de interlíngua: estudo longitudinal centrado na } \\
\text { oralidade de sujeitos brasileiros aprendizes de espanhol. } 2001.314 \mathrm{f} \text {. Tese } \\
\text { (Doutorado em Linguística Aplicada) - Universidade Estadual de Campinas, } \\
\text { Campinas, 2001. }\end{array}$ \\
\hline 6 & 2002 & UNESP & $\begin{array}{l}\text { FANJUL, A. P. Deslocando a proximidade. Discursividade no contato } \\
\text { português-espanhol. 2002. } 219 \text { f. Tese (Doutorado em Letras/Linguística e } \\
\text { Língua Portuguesa) - Universidade Estadual Paulista Júlio de Mesquita } \\
\text { Filho, Araraquara, 2002. }\end{array}$ \\
\hline 7 & 2002 & UFRGS & $\begin{array}{l}\text { VILLALBA, T. K. B. Pepe vio que no tiene jeito, su mujer es asímismo: as } \\
\text { delicadas relaçóes lexicais entre a L1 e a L2 na aquisição de espanhol por } \\
\text { universitários brasileiros. 2002. } 249 \text { f. Tese (Doutorado em Letras) - } \\
\text { Universidade Federal do Rio Grande do Sul, Porto Alegre, 2002. }\end{array}$ \\
\hline 8 & 2003 & $\begin{array}{l}\text { UNICA } \\
\text { MP }\end{array}$ & $\begin{array}{l}\text { PEDROSO, S. F. Literatura e tradução no ensino de espanhol-língua } \\
\text { estrangeira. 2003. } 245 \mathrm{f} \text {. Tese (Doutorado em Linguística Aplicada) - } \\
\text { Universidade Estadual de Campinas, Campinas, 2003. }\end{array}$ \\
\hline 9 & 2004 & UNESP & $\begin{array}{l}\text { CARVALHO, K. C. H. P. Descrição fonético-acústica das vibrantes no } \\
\text { português e no espanhol. 2004. } 205 \text { f. Tese (Doutorado em Letras) - } \\
\text { Universidade Estadual Paulista Júlio de Mesquita Filho, Assis, } 2004 .\end{array}$ \\
\hline 10 & 2004 & UFAL & $\begin{array}{l}\text { SILVA, E. B. As relações semânticas de polissemia e homonímia para um } \\
\text { tratamento de heterossemânticos na interface portuguê-espanhol. } 2004.337 \\
\text { f. Tese (Doutorado em Letras e Linguística) - Universidade Federal de } \\
\text { Alagoas, Maceió, } 2004 \text {. }\end{array}$ \\
\hline 11 & 2004 & UFBA & $\begin{array}{l}\text { SOUZA, C. G. A. O componente sócio-pragmático nas aulas de espanhol } \\
\text { como língua estrangeira: os diálogos em Mafalda como modelo de } \\
\text { interação social. } 2004.159 \mathrm{f} \text {. Tese (Doutorado em Letras e Linguística) - } \\
\text { Universidade Federal da Bahia, Salvador, 2004. }\end{array}$ \\
\hline 12 & 2006 & USP & $\begin{array}{l}\text { BRUNO, F. A. T. C. Lo que uno/a,comprende lo que uno/a dice - } \\
\text { compreensão e produção do espanhol como língua estrangeira por adultos } \\
\text { brasileiros em situação de ensino e aprendizagem. 2006. } 250 \mathrm{~F} \text {. Tese } \\
\text { (Doutorado em Letras) - Departamento de Letras Modernas Língua } \\
\text { Espanhola e Lit. Espanhola e Hispano-americana. Universidade de São } \\
\text { Paulo, São Paulo, 2006. }\end{array}$ \\
\hline 13 & 2007 & UFRJ & $\begin{array}{l}\text { CORREA, P. A. P. A expressão da mudança de estado na interlíngua de } \\
\text { brasileiros aprendizes de espanhol. 2007. } 267 \text { f. Tese (Doutorado em } \\
\text { Linguística). Universidade Federal do Rio de Janeiro, Rio de Janeiro, } 2007\end{array}$ \\
\hline
\end{tabular}




\begin{tabular}{|c|c|c|c|}
\hline & Ano & $\begin{array}{l}\text { Univer- } \\
\text { sidade }\end{array}$ & Doutorado \\
\hline 14 & 2007 & UEL & $\begin{array}{l}\text { FERREIRA, C. C. O imperativo em gramáticas e em livros didáticos de } \\
\text { espanhol como língua estrangeira visto sob a ótica dos modelos de análise } \\
\text { contrastiva e de análise de erros. } 2007.527 \mathrm{f} \text {. Tese (Doutorado em Estudos } \\
\text { da Linguagem). Universidade Estadual de Londrina, Londrina, } 2007 \text {. }\end{array}$ \\
\hline 15 & 2007 & USP & $\begin{array}{l}\text { FONSECA, M. C. M. A semântica e a pragmática na compreensão das } \\
\text { oposições } \square \text { resente perfect X past simple do inglês e pretérito perfecto X } \\
\text { pretérito indefinido do espanhol. 2007. } 229 \mathrm{f} \text {. Tese (Doutorado em } \\
\text { Linguística) - Universidade de São Paulo, São Paulo, } 2007 .\end{array}$ \\
\hline 16 & 2007 & USP & $\begin{array}{l}\text { GOLÇALVES, E. Marcadores conversacionais na interlíngua de } \\
\text { aprendizes de espanhol no Brasil. 2007. } 148 \text { f. Tese (Doutorado em } \\
\text { Filologia e Língua Portuguesa) - Universidade de São Paulo, São Paulo, } \\
2007 .\end{array}$ \\
\hline 17 & 2008 & UNESP & $\begin{array}{l}\text { GREGOLIN, I. V. Estratégias de cortesia em língua espanhola: estudo de } \\
\text { caso em fórum online com participantes brasileiros. 2008. } 166 \text { f. Tese } \\
\text { (Doutorado em Letras/Linguística e Língua Portuguesa) - Universidade } \\
\text { Estadual Paulista Júlio de Mesquita Filho, Araraquara, 2008. }\end{array}$ \\
\hline 18 & 2008 & PUC-RJ & $\begin{array}{l}\text { RAZUK. R. O. Do Inglês L1 ao Português L3 passando pelo Espanhol L2: } \\
\text { transferências em regência/transitividade verbal, com foco nas preposições. } \\
2008.324 \text { f. Tese (Doutorado em Letras) -Departamento de Letras, } \\
\text { Pontífica Universidade Católica do Rio de Janeiro, Rio de Janeiro, } 2008 .\end{array}$ \\
\hline 19 & 2009 & UFRJ & $\begin{array}{l}\text { PINTO, M. S. Transferências prosódicas do português do Brasil/LM na } \\
\text { aprendizagem do espanhol/LE: enunciados assertivos e interrogativos } \\
\text { totais. 2009. } 355 \text { f. Tese (Doutorado em Letras Neolatinas) - Universidade } \\
\text { Federal do Rio de Janeiro, Rio de Janeiro, 2009. }\end{array}$ \\
\hline 20 & 2010 & UEL & $\begin{array}{l}\text { ANDRADE, O. G. Necessidades léxicas de universitários brasileiros } \\
\text { aprendizes de espanhol: levantamento, descrição e análise. 2010 . } 267 \mathrm{f} \text {. } \\
\text { Tese (Doutorado em Estudos da Linguagem). Universidade Estadual de } \\
\text { Londrina, Londrina, 2010. }\end{array}$ \\
\hline 21 & 2010 & UFPR & $\begin{array}{l}\text { DIAS, L. S. Estratégias de polidez linguística na formulação de pedidos e } \\
\text { ordens contextualizados: um estudo constrastivo entre o português } \\
\text { curitibano e o espanhol. 2010. } 209 \text { f. Tese (Doutorado em Letras). } \\
\text { Universidade Federal do Paraná, Curitiba, } 2010 .\end{array}$ \\
\hline 22 & 2010 & USP & $\begin{array}{l}\text { LIMA, E. I. A. S. Análise das dificuldades dos estudantes brasileiros de } \\
\text { E/LE na percepção e na produção dos sons aproximantes e nasais em } \\
\text { língua espanhola. } 2010.131 \mathrm{f} \text {. Tese (Doutorado em Letras) - Departamento } \\
\text { de Letras Modernas Língua Espanhola e Lit. Espanhola e Hispano- } \\
\text { americana. Universidade de São Paulo, São Paulo, 2010. }\end{array}$ \\
\hline
\end{tabular}

